\title{
Combined Factors for Predicting Cognitive Impairment in Elderly Population Aged 75 Years and Older: From a Behavioral Perspective
}

OPEN ACCESS

Edited by:

Gao-Xia Wei,

Institute of Psychology (CAS), China

Reviewed by:

Antonio Aquino,

University of Studies G. d'Annunzio

Chieti and Pescara, Italy

Wei Fan,

Hunan Normal University, China

${ }^{*}$ Correspondence:

Zhixiong Yan

yanzx@nnnu.edu.cn

Specialty section

This article was submitted to

Cognitive Science,

a section of the journal

Frontiers in Psychology

Received: 03 May 2020

Accepted: 07 August 2020

Published: 10 September 2020

Citation:

Yan Z, Zou X and Hou X (2020)

Combined Factors for Predicting

Cognitive Impairment in Elderly Population Aged 75 Years and Older:

From a Behavioral Perspective.

Front. Psychol. 11:2217.

doi: 10.3389/fpsyg.2020.02217

\section{Zhixiong Yan ${ }^{1 *}$, Xia Zou ${ }^{2,3}$ and Xiaohui Hou ${ }^{1}$}

${ }^{1}$ Psychology Department, Nanning Normal University, Nanning, China, ${ }^{2}$ Guangxi College for Preschool Education, Nanning, China, ${ }^{3}$ Faculty of Industrial Education and Technology, King Mongkut's Institute of Technology Ladkrabang, Bangkok, Thailand

To unravel the combined effect of risk and protective factors that may contribute to preserve or impair cognitive status, this prospective cohort study systematically investigated a cluster of factors in elders aged 75 years and older from Guangxi Longitudinal Cohort (GLC) dataset. GLC has tracked 630 oldest-elders for two times within 2 years and will continue to follow two times in the next 4 years. At baseline geriatric assessment, sociodemographic information (e.g., education, Mandarin, marriage, and income), physical status [body mass index (BMI), chronic disease/medicine], lifestyle factors (smoking, alcohol, and exercise), and self-rated mental health (self-care, well-being, anxiety) were recorded by online interview. With 2 years' follow-up, Mini-Mental State Examination (MMSE) and memory test were performed through person-to-person interview. The performance of MMSE was applied to represent the responder's cognitive status which classified into cognitive impairment and normal group based on a cutoff point of 20. An age-related cognitive declining trend of 15 stratified factors was observed, though with a small effect size (Rsquare: 0.001-0.15). The odds of exposure or non-exposure on factors (memory, self-care, exercise, income, education, and literacy) had a significantly different effect on cognitive impairment through multivariate analysis after adjusting other confounding variables. Through stepwise multiple logistic regression analysis, the following 12 factors/index would be integrated to predict cognitive impairment: gender, physical health factors (BMI, chronic disease), socioeconomic and lifestyle factors (education, literacy, Mandarin, marriage, income, and exercise), and psychological health factors (memory, self-care cognition, and anxiety). Related clinical and nursing applications were also discussed.

Keywords: cognitive impairment, protective/risk factors, elderly population, lifestyle, logistic regression

\section{INTRODUCTION}

Cognitive impairment, such as deterioration in memory, attention, and language, was considered as an inevitable trend of aging experienced by majority of elderly people (Folstein et al., 1985), the extent of which is strongly affected by individual variables (e.g., lifestyle, socioeconomic status) and their interactions. For someone, 
even the detail of experienced things could clearly be recalled, while some peers could not remember their own name. In current decades, the prevalence of cognitive impairment (e.g., mild cognitive impairment and dementia) has increased dramatically (Boyle et al., 2006) and considerable interest was attached in science research community (Deary et al., 2009). Taking China as an example, the estimated annual expenditures for cognitive impairment in the elderly population are predicted to be US $\$ 69$ billion in 2020, which stressed a detrimental effect on family and other carers (Xu et al., 2017). As chronic and complicated characteristics, the effect of medical intervention to modify the course of cognitive impairment has not been effective and even hard to clearly attenuate impairment progression (Rocca et al., 2011). For cognitive impairment may be an agent of lifestyle-based causes, potentially modifiable behavioral factors are alternative to delay the onset of cognitive impairment (Friedman et al., 2015).

Accumulating epidemiological evidence indicates that psychological, environmental, and social factors can help to alleviate cognitive impairment and improve cognitive preservation (Wang et al., 2006; Rocca et al., 2011; Roberts et al., 2015; Arnau et al., 2016; Clare et al., 2017; Klimova et al., 2017; Lamblin et al., 2017; Zhang et al., 2017). A healthy lifestyle (refraining from smoking, moderate alcohol consumption, more physical activity/cardiorespiratory fitness, a Mediterranean-style diet, and more social and mentally stimulating activity) was associated with better cognitive performance and resilience (Hughes and Ganguli, 2009; Fung et al., 2011; Bielak et al., 2014; Dardiotis et al., 2014; Satizabal et al., 2016; Bubbico et al., 2019). Socioeconomic adversities (e.g., illiteracy, poor occupational achievement, and low income) could be potentially attributed to dementia (Scazufca et al., 2010). However, the measurements of these studies were heterogeneous with cross-sectional design and partial epidemiological factors. Comprehensive factors assessment and prediction were still lacking. Few studies have systematically examined the odds of the exposure and non-exposure of lifestyle factors. Moreover, exploring factors in a comprehensive and aggregated way would be a promising direction for preserving cognitive capacity. Thus, a systematic exploration of these factors is needed, and aggregately considering them was emphasized in current research. To collect factors in multiple level and as rich as possible, we classified the factors in lifestyle, socioeconomic, psychological, and physical aspect. Several pivotal modifiable factors associated with cognitive impairment will be refined after exploring the effect of each factor. The application for elder people and clinicians was suggested.

Besides, the diagnostic methods such as mild cognitive impairment (MCI) measurement were time-consuming and impractical for aging community survey (Rohrer et al., 2005). As a valid and brief tool of mental state assessment, Mini-Mental State Examination (MMSE, 30 items as well as 5-10 min testing time) covered a variety of cognitive competencies including orientation, memory, attention, reading, and writing with good identification property (Folstein et al., 1975). Here, the current study applied MMSE as a primary tool to measure cognitive impairment of elder individuals aged 75 years above. The aim of this study is to conduct a systematic analysis of factors and explore which is the best combination of protective and risk factors of cognitive impairment.

\section{MATERIALS AND METHODS}

\section{Subjects}

A total of 788 subjects with normal cognitive function aged 75 years and above were randomly collected at baseline based on census track in 13 communities according to Guangxi Longevity Cohort Project (GLCP). After 2 years' interval, the final sample consisted of 630 subjects (259 males, 371 females, mean age: 84.23) through interview in person (Figure 1). Subjects who died (81), not reached (30), and disconnected (47) were excluded from the following data analysis. The following participation rate was $80 \%$.

\section{Factors and Stratified Criteria}

At baseline, multidimensional factors were collected in sociodemographic characteristics (gender, the number of children, marriage, income, education, and Mandarin), lifestyle factors (smoking, alcohol, and exercise), physical status [body mass index (BMI), eyesight, chronic disease/medicine], and selfrated mental health factors (self-care, well-being, and anxiety) through telephone interview. Subjects were asked questions such as: How do you think your well-being? Are you a smoker? How many cigarettes do you smoke per day? The interviewer recorded the answer in specific points based on the subject's response. All variables were stratified into two or four levels.

\section{Sociodemographic Characteristics}

Sociodemographic information was available regarding gender, age, up-bring children, education, Mandarin, and income. The number of children was divided as three children or more and less than three children. Marriage was classified as married and unmarried (including single, divorced, or widowed). Income grouped by more than $500 \mathrm{RMB}$ and less than 500 RMB. Education was grouped as uneducated (never received education), less than 5 years, and more than 5 years. Mandarin was classified as capable (understanding and speaking Mandarin) and unable (cannot understand and speak Mandarin) groups.

\section{Physical Health Factors}

A brief measure of physical functioning was based on three separate tests of physical ability, regarding BMI (subject's weight in kilograms divided by the square of height in meters), eyesight, and chronic disease/medicine condition. Subjects whose BMI $<18.5$ were taken as underweight, $>24$ as overweight and range between 18.5 and 24 as normal. Eyesight was divided by normal (eyesight test $<1.0$ ) and abnormal (eyesight test $>1.0$ ) groups. Chronic disease/Medicine had two levels (taking, none) according to having chronic disease 


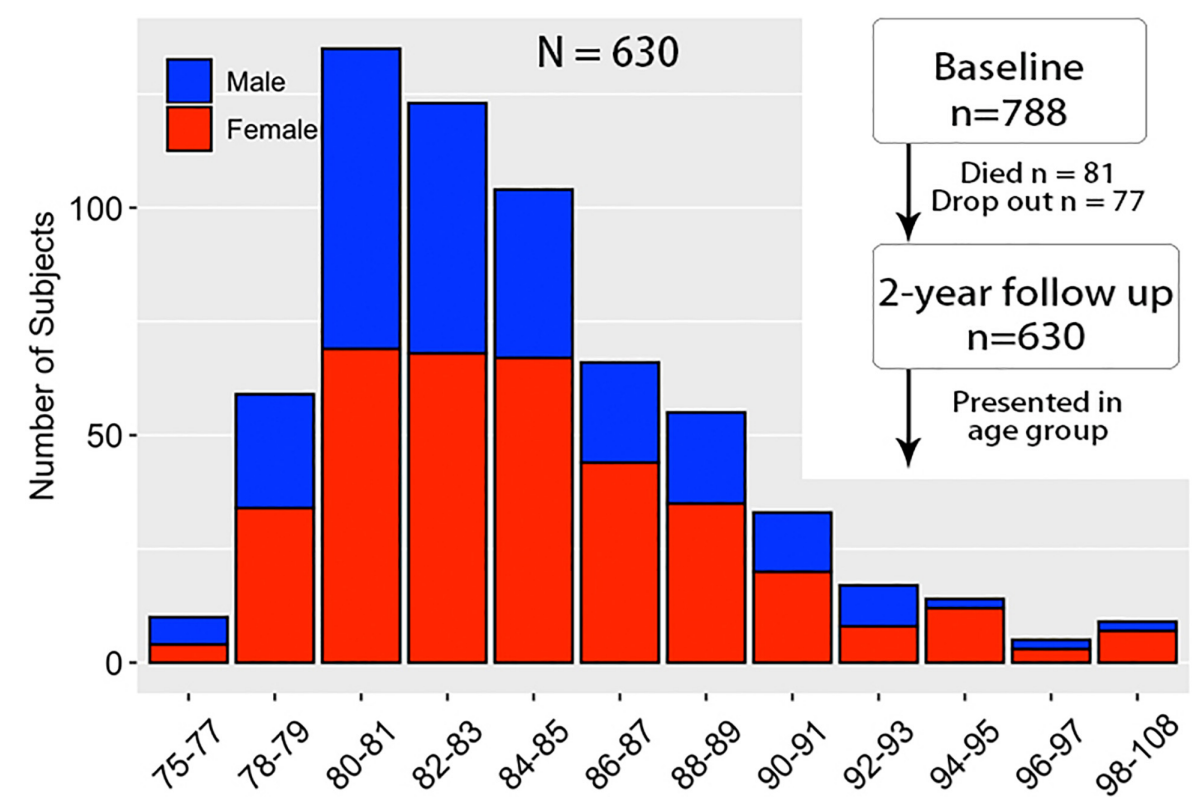

FIGURE 1 | Subjects age-group distribution and collection flowchart.

(like cardiovascular disease, respiratory disease) and taking medicines or not.

\section{Lifestyle Factors}

Smoking was classified as no smoking and smoking, whereas alcohol consumption was grouped into alcohol consumption and no alcohol consumption. Exercise was classified as $>50$ min per day and $<50$ min per day.

\section{Self-Rated Mental Health}

Self-rated mental health factors (anxiety, well-being, and selfcare) were recorded by a single-item question with five alternative choices regarding excellent (receiving 5 points), very good (receiving 4 points), good (receiving 3 points), fair (receiving 2 points), and poor (receiving 1 point). Each specific component (like anxiety) was then divided into three stratified levels as low level (1-2 points), moderate level (3 points), and high level (45 points).

\section{Follow-Up Assessment}

With 2-year follow-up, the evaluation including two tests was conducted by coordinator interviewer in person. One test was MMSE (Molloy, 2014) as an index of cognitive status in which subjects are assigned into two groups, the cutoff point for the MMSE performance was 20. MMSE was commonly used to distinguish subjects into with and without cognitive impairment (Uffelen et al., 2008). MMSE score above 20 grouped into normal group, whereas score below 20 was treated as cognitive impairment group.

To validate the cognitive measurement, digit span test was utilized as supplemental cognitive measurement in addition to protective risk in which included 17 items (sequential memory: nine items; reversed order memory: eight items). Each item had 1 point if a subject gave a correct answer. According to the performance of the digit span task, memory was classified as four groups according to the sum of points: excellent $(>11.5)$, good $(>7.86)$, medial $(\geq 4.2)$, weak $(<4.2)$.

In the spirit of collaboration and open science, the data are available for application and can be freely accessed at data sharing part in our lab web page: http://yanlab.club/index.php/info/128. html.

\section{Statistical Analyses}

All statistical analyses were performed in Epicalc (Chongsuvivatwong, 2007), an epidemiological data analysis tool in R. The data with missing records were omitted before statistical analyses. The function $l m$ based on the least squares method was used to perform age-related linear modeling for each factor. The attributes of $\beta$ (coefficients of the independent variables) and R-square (effect size) were calculated (Figure 2). Multivariate analyses using logistic regression models $(\mathrm{glm})$ were conducted to identify the effect of exposure and nonexposure in specific factors on cognitive impairment in which crude odds ratio (OR) and adjusted OR (adjusted for other variables) were conducted (Table 1). Stepwise logistic regression (step) was followed for removing non-significant independent variables according to Akaike's Information Criterion (AIC) in which the optimal model with the lowest AIC value showed high likelihood or best fit. Specifically, the step removes each independent variable and compares the degrees of freedom reduced, the new deviance, and the 

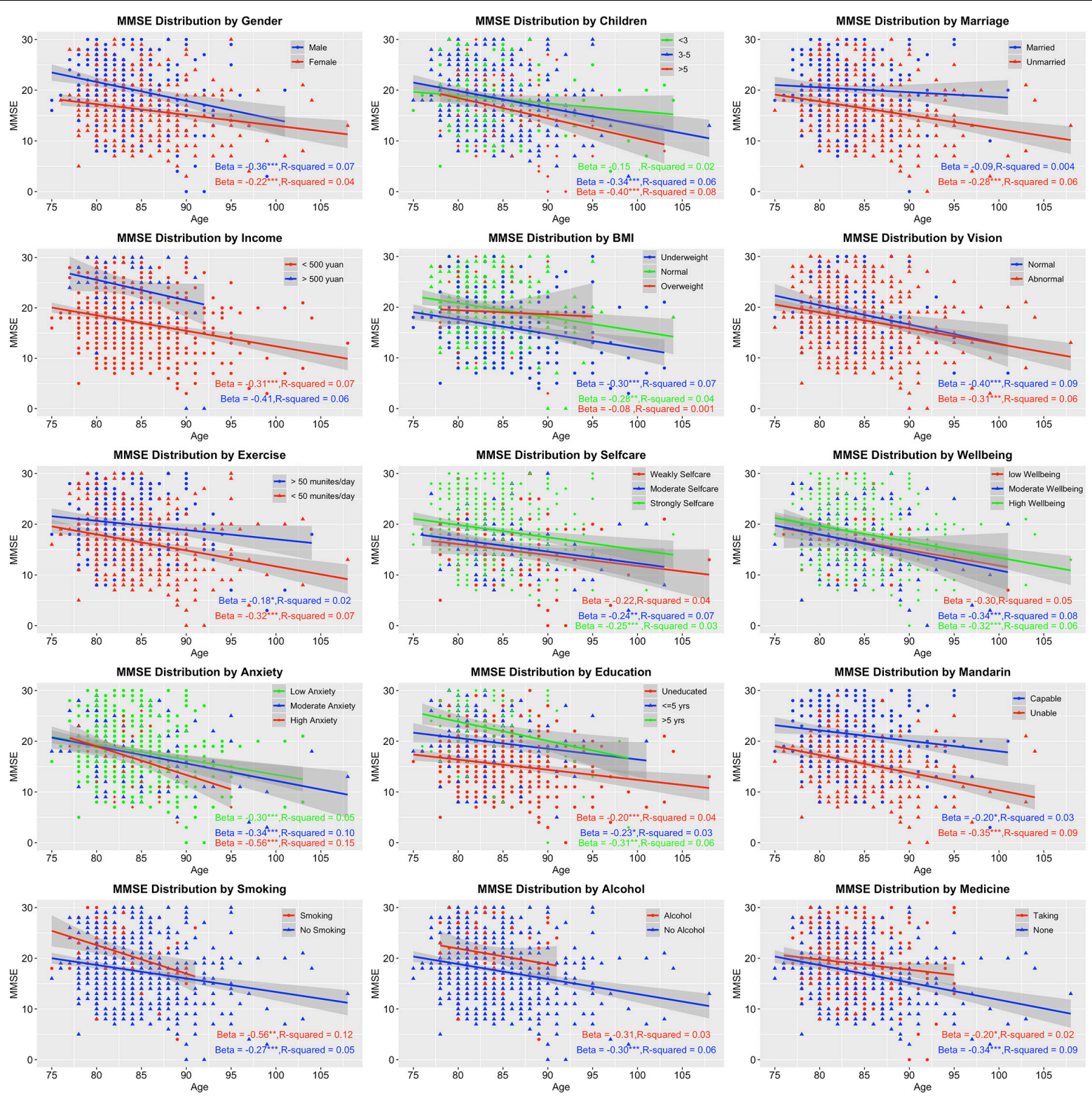

FIGURE 2 | Age-related trends of cognitive changes by stratified factors. The vertical axis presents Mini-Mental State Examination (MMSE) score symbolizing cognitive statue; the horizontal axis presents age. Beta (the strength of association) and R-square (effect size) of each stratified factor were also calculated. ${ }^{*} p<0.05 ;{ }^{* \star} p<0.01 ;{ }^{* \star *} p<0.001$.

new AIC. The results are increasingly sorted by AIC. The top one having the lowest AIC is the best one (Step 6 in Table 2).

\section{RESULTS}

\section{Age-Related Trajectories of Cognitive Changes via Stratified Factors}

A linear declining trend was found in all factors stratified in two to four levels (Figure 2). Several factors showed stronger decreasing tendency such as high anxiety $(\beta=-0.56)$ and smoking ( $\beta=-0.56)$, while others like married condition ( $\beta=$ $0.09)$ and overweight $(\beta=-0.08)$ showed weaker associations. Unfortunately, all associations only reached small effect sizes $\left(R^{2}\right.$ from 0.001 to 0.15 ).

\section{The Effects of Exposure and Non-exposure in Specific Stratified Factors}

In multivariate regression analysis on which the effects of exposure and non-exposure were checked (Table 1), the most significant factor that contributed to cognitive impairment was 
TABLE 1 | The exposure and non-exposure effects of risk factors on cognitive impairment.

\begin{tabular}{|c|c|c|c|c|c|c|}
\hline & Factors & Crude OR & $95 \% \mathrm{Cl}$ & Adj. OR & $95 \% \mathrm{Cl}$ & $p$ (Wald's test) \\
\hline \multirow[t]{2}{*}{ Age } & 75 & 1.00 & & & & \\
\hline & $75+1$ & 1.09 & $1.05-1.14$ & 1.01 & $0.95-1.07$ & 0.78 \\
\hline \multirow[t]{2}{*}{ Gender } & Male & 1.00 & & & & \\
\hline & Female & 3.74 & $2.58-5.41$ & 1.58 & $0.85-2.94$ & 0.15 \\
\hline \multirow[t]{2}{*}{ Children } & 0-2 & 1.00 & & & & \\
\hline & $>3$ & 1.01 & $0.66-1.55$ & 1.11 & $0.58-2.10$ & 0.75 \\
\hline \multirow[t]{3}{*}{ BMl } & Normal & 1.00 & & & & \\
\hline & Low-weight $(<18.5)$ & 3.07 & $2.08-4.53$ & 1.56 & $0.91-2.68$ & 0.11 \\
\hline & Over-weight (> 24) & 1.20 & $0.66-2.21$ & 1.05 & $0.40-2.74$ & 0.92 \\
\hline \multirow[t]{3}{*}{ Self-care } & Medial & 1.00 & & & & \\
\hline & Weak & 0.63 & $0.28-1.44$ & 0.22 & $0.07-0.70$ & $0.01^{*}$ \\
\hline & Strong & 0.23 & $0.11-0.43$ & 0.21 & $0.09-0.50$ & $<0.001^{\star \star \star}$ \\
\hline \multirow[t]{3}{*}{ Well-being } & Medial & 1.00 & & & & \\
\hline & Weak & 1.42 & $0.58-3.51$ & 1.79 & $0.52-6.15$ & 0.35 \\
\hline & Strong & 0.74 & $0.46-1.18$ & 1.26 & $0.63-2.52$ & 0.52 \\
\hline \multirow[t]{3}{*}{ Anxiety } & Medial & 1.00 & & & & \\
\hline & Weak & 1.02 & $0.64-1.65$ & 1.76 & $0.89-3.49$ & 0.10 \\
\hline & Strong & 1.35 & $0.63-2.88$ & 1.64 & $0.58-4.64$ & 0.35 \\
\hline \multirow[t]{3}{*}{ Education } & None & 1.00 & & & & \\
\hline & $1-5$ years & 0.21 & $0.13-0.32$ & 0.77 & $0.38-1.55$ & 0.46 \\
\hline & $>5$ years & 0.08 & $0.05-0.13$ & 0.34 & $0.14-0.83$ & $0.02^{*}$ \\
\hline \multirow[t]{2}{*}{ Literacy } & Literate & 1.00 & & & & \\
\hline & Illiterate & 9.59 & $6.33-14.52$ & 2.92 & $1.41-6.05$ & $0.004^{\star \star}$ \\
\hline \multirow[t]{2}{*}{ Mandarin } & Able & 1.00 & & & & \\
\hline & Unable & 5.17 & $3.49-7.54$ & 1.45 & $0.79-2.68$ & 0.23 \\
\hline \multirow[t]{2}{*}{ Marriage } & Married & 1.00 & & & & \\
\hline & Unmarried & 3.02 & $2.10-4.36$ & 1.35 & $0.77-2.35$ & 0.30 \\
\hline \multirow[t]{2}{*}{ Income } & Low (< 500 yuan) & 1.00 & & & & \\
\hline & High (> 500 yuan) & 0.10 & $0.05-0.20$ & 0.32 & $0.12-0.84$ & $0.02^{*}$ \\
\hline \multirow[t]{2}{*}{ Smoking } & Smoking & 1.00 & & & & \\
\hline & Non-smoking & 2.54 & $1.52-4.26$ & 0.90 & $0.41-1.96$ & 0.79 \\
\hline \multirow[t]{2}{*}{ Alcohol } & Drinking & 1.00 & & & & \\
\hline & Non-drinking & 2.58 & $1.51-4.41$ & 1.19 & $0.55-2.56$ & 0.65 \\
\hline Chronic disease/ & Taking & 1.00 & & & & \\
\hline Medicine & Never & 1.51 & $1.06-2.15$ & 1.26 & $0.74-2.13$ & 0.39 \\
\hline \multirow[t]{2}{*}{ Exercise } & High (> 50) & 1.00 & & & & \\
\hline & Low $(<50)$ & 2.50 & $1.74-3.58$ & 3.10 & $1.80-5.31$ & $<0.001^{\star \star \star}$ \\
\hline \multirow[t]{4}{*}{ Memory } & Excellent & 1.00 & & & & \\
\hline & Good & 6.14 & $3.27-11.56$ & 4.84 & $2.25-10.39$ & $<0.001^{\star \star \star}$ \\
\hline & Medial & 24.98 & $11.90-52.46$ & 12.21 & 4.90-30.42 & $<0.001^{\star \star *}$ \\
\hline & Weak & 55.05 & $21.00-144.30$ & 36.78 & $11.62-136.44$ & $<0.001^{\star \star \star}$ \\
\hline
\end{tabular}

BMI, body mass index; $\mathrm{Cl}$, confidence interval. ${ }^{*} p<0.05,{ }^{* *} p<0.01,{ }^{* * *} p<0.001$.

memory. Compared to excellent memory subjects, five times increase in the odds of cognitive impairment, 12.21 times and 36.78 times for medial and weak memory subjects, respectively. Another significant mental health factor was self-care. Compared to medial level, weak level and strong level had only 0.22 and 0.21 times to developing cognitive impairment. Similarly, there are three sociodemographic factors that played as protective factors. As to non-education, subjects who received 1-5 years of education had only 0.77 times possibility resulting in cognitive impairment. If receiving education $>5$ years, the odds decreased to 0.34 times. Similar to education, illiterate subjects had 2.92 times suffering cognitive impairment compared to literate subjects. Income is a representative index for subject's economic status, by which high-income subjects (> 500 yuan per month) had just 0.32 times led to cognitive abnormal referenced to low-income ones ( $<500$ yuan per month). Among lifestyle factors, the influence of physical exercise $<50 \mathrm{~min} /$ day had 3.1 times odds to lead to cognitive impairment compared to exercise $>50 \mathrm{~min} /$ day. Other factors did not show pronounced difference between exposure and non-exposure. 
TABLE 2 | Crucial factors predicting cognitive impairment by stepwise regression.

\begin{tabular}{lcccccc}
\hline & Step 1 & Step 2 & Step 3 & Step 4 & Step 5 & Step 6 \\
\hline Age & + & + & & & & \\
Gender & + & + & + & + & + & + \\
Children & + & + & + & + & + & \\
BMl & + & + & + & + & + & + \\
Self-care & + & + & + & + & + & + \\
Well-being & + & & & & & \\
Anxiety & + & + & + & + & + & + \\
Edu & + & + & + & + & + & + \\
Literacy & + & + & + & + & + & + \\
Mandarin & + & + & + & + & + & + \\
Marriage & + & + & + & + & + & + \\
Income & + & + & + & + & + & + \\
Smoke & + & + & + & & & \\
Alcohol & + & + & + & + & & \\
Chronic disease/Medicine & + & + & + & + & + & + \\
Exercise & + & + & + & + & + & + \\
Memory & + & + & + & + & + & + \\
AlC & 457.08 & 454.04 & 452.12 & 450.22 & 448.36 & 446.58
\end{tabular}

BMI, body mass index; Edu, received education years; AIC, Akaike's Information Criterion, in which a low value shows a high likelihood or a good fit. Each column shows an alternative model, the model of Step 6 was found as the optimal model with the lowest AIC.

\section{The Aggregated Factors That Best Predict Cognitive Impairment}

To check whether some crucial factors could combine to predict cognitive impairment as the optimal model, stepwise regression analysis was conducted (Figure 3 and Table 2). The Step 6 was taken as the optimal model for which its lowest AIC value showed the best fitting results (466.58). The model encompassed Gender, BMI, Self-care cognition, Anxiety, Education, Literacy, Mandarin, Marriage, Income, Chronic disease/Medicine, Exercise, and Memory. Those factors may be more effective when they are combined to predict and intervene cognitive impairment for elderly populations aged 75 and older.

\section{DISCUSSION}

As lifestyle and other factors played an enduring and interacted way in the cognitive aging process, uncovering the protective or risk effect on cognitive impairment was a great challenge. Though numerous findings indicated that lifestyle and other sociodemographic factors impacted on cognitive performance (Mensink et al., 1997; Walsh, 2011; Roberts et al., 2015; Zhang et al., 2017; Clare et al., 2017), it is hard to explore the precise mechanism of each factor on cognitive change. Taking the determinants together would be a promising alternative to comprehensively consider protective or risk factors.

In the present study, a similar age-related decreasing trend of cognitive status was found in each stratified factor. Each factor independently contributed to cognitive impairment but with a limited effect size (Deary et al., 2009). Besides, a

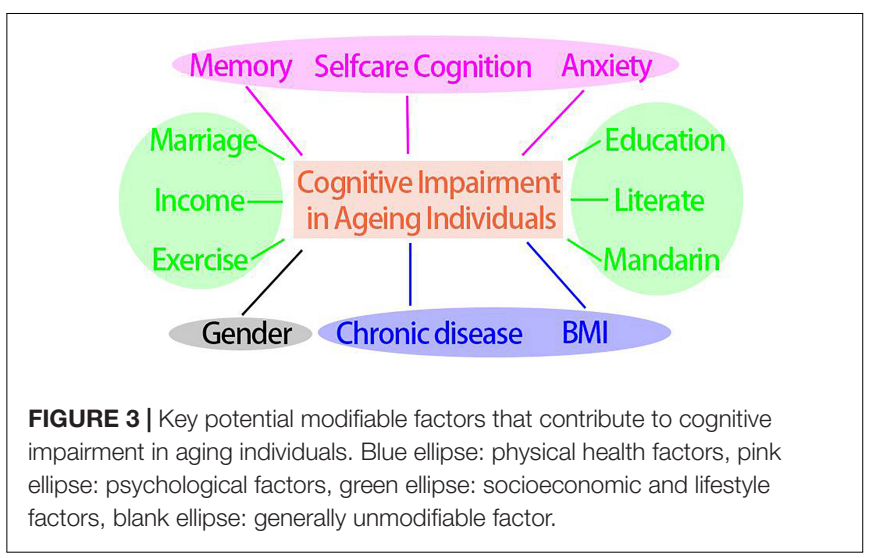

pronounced exposure effect was found in the following risks via multivariate regression analysis: lifestyle factor (physical activity/exercise), socioeconomic factors (education, literacy, income), psychological health factor (self-care cognition), and memory. Exposure in these factors made dramatically different chances to be onset of cognitive impairment. Taking memory as an illustration, the risks of cognitive impairment increased more than 36 times among weak memory individuals compared to that of excellent memory ones. It would be reasonable to infer that working memory stimulation tasks may be one of the most beneficial approaches for preserving and improving cognitive capacity in elder adults. A working memory intervention study also suggested that memory training was an effective way for maintaining normal cognitive function (Heinzel et al., 2014). As for other factors in the current study, low-level exercise ( $<50 \mathrm{~min} /$ day $)$ responders had 3.1 times odds to suffer from cognitive impairment in comparison with high-level exercisers. It means that the value of physical activity was not limited in improving cardiovascular function but also can benefit psychological processes or brain health (e.g., delay cognitive decline) (Gregory et al., 2001). Regular fitness made great contribution to decreased mortality and morbidity rates (Gregory et al., 2001; Salmon, 2001; Uffelen et al., 2008). Other evidence also suggested that increased aerobic exercise was associated with structural and functional changes in elders' brain (Colcombe et al., 2006; Wei et al., 2014). Besides, other crucial sociodemographic factors such as education, literacy, and income also played a vital role in reserving cognitive status. Further evidence about their beneficial impact can be found in numerous aging studies (Perna et al., 2012; Calasanti, 2016; Livingston et al., 2017; Scarmeas et al., 2018).

Above all, as various causes led to cognitive decline in later life, exploring factors in an isolated approach was insufficient to explain cognitive impairment systematically. Instead, it would be appropriate to aggregate multifaceted factors into a unified profile. Only by doing so could clinical guidelines or healthy recommendation be efficient and appropriate, which was also suggested by review work (Plassman et al., 2010) from which a comprehensive consideration of risk and protective factors was necessary when drawing firm 
conclusions about associations with cognitive decline. The findings in the present study suggested that protective and risk factors were influenced by a number of potentially modifiable variables that could be targets for interventions to promote and reserve better cognitive function. Based on our analysis, the following four types including 12 factors/index would be considered to integrate for predicting cognitive impairment: gender, physical health factors (BMI, chronic disease), socioeconomic and lifestyle factors (education, literacy, Mandarin, marriage, income, and exercise), and psychological health factors (memory, self-care cognition, and anxiety). These potentially modifiable factors (gender excepted) showed promise in preserving cognitive capacity. Targeting these vital factors could help to reduce the incidence of cognitive impairment or substantially delay its onset (Colcombe et al., 2006). It would be constructive to encourage elder people using cognitive stimulation games/activities, like video games, playing cards, language learning, and so on, in which could enormously remedy deficiencies in education or literacy and improve well-being (Charness and Boot, 2009). Meanwhile, physical activity and psychological well-being are also recommended in nursing or clinical practice (McAuley and Rudolph, 1995; Ruuskanen and Ruoppila, 1995; McAuley et al., 2006). Taken together, each factor alone might manifest a spurious and faint association. A comprehensive considering those factors could be valid for predicting cognitive change and preserving cognitive capacity.

Besides, we did not observe significant associations between age and functional impairment. Previous study suggested that age was a major risk factor for cognitive decline (Deary et al., 2009). The reason may be the range of time in the current study was based on only 2 years, not a decade as a previous study (Guralnik et al., 1993). Therefore, the limited segment in our study would be insufficient to reflect the accumulated aging effect. Besides, the effects of smoking and alcohol drinking on cognitive decline were not found to be statistically significant, which was debated in previous evidence (Clare et al., 2017). Evidence was growing that moderate levels of alcohol intake may have a protective effect against dementia and cognitive decline compared with either abstinence or heavy drinking (Ganguli et al., 2005). Moreover, the crude dichotomous classification in our study might conceal the cognitive associations. More precise measurement according to actual consumption was necessary in future studies.

Several other limitations are also needed to be concerned carefully. Firstly, the subjects who participated in the present study came from a remote rural area of China. The external validity of cognitive status reduced and limited its generality. Also, an underestimated cognitive performance may occur for subjects who had relatively lower education and economic status than other older population living in an urban area. Thus, replicating investigation with larger samples and participants living in the city is necessary in future study. Secondly, we did not record information on genetic contribution, brain imaging evidence, healthy dietary habits, and emotional and social support factors, which have previously demonstrated associations with cognitive impairment (Dardiotis et al., 2014).
Especially the related social factors, for social organizations are organism-like systems, such as in-group entitativity, which may play as a crucial protective factor for cognitive impairment and improve their life quality in terms of group support and wellbeing (Campbell, 1958; Pagliaro et al., 2013; Bubbico et al., 2019). Last but not least, we only utilized MMSE and digit span memory test as the measurement of cognitive function which limited the validation and generality of the results we found, though MMSE and digit memory test strongly associated and mutually confirmed the trends of cognitive aging process. Other objective measures, such as electrophysiological and brain imaging technologies, needed to address in future studies. More refined experimental design was also needed to make the protective and risk factors more valid and propel clinical application in cognitive aging field.

\section{CONCLUSION}

The comprehensive risk and protective effects of sociodemographic, lifestyle, and mental health on cognitive impairment were observed in subjects aged 75 years and older. We found an age-related declining trend of cognitive capacity in each stratified factor with slight diversity associations. The small effect size (R-square: 0.001-0.15) of individual factor suggests that a combined consideration of factors would be appropriate for clinical application and intervention.

\section{DATA AVAILABILITY STATEMENT}

The raw data supporting the conclusions of this article will be made available by the authors, without undue reservation, to any qualified researcher.

\section{ETHICS STATEMENT}

The studies involving human participants were reviewed and approved by the Institutional Review Boards of Nanning Normal University. The patients/participants provided their written informed consent to participate in this study.

\section{AUTHOR CONTRIBUTIONS}

ZY conceived the idea, designed the study, analyzed and interpreted the data, and drafted part of the manuscript. XZ and $\mathrm{XH}$ assisted with the analysis and interpretation of data. XZ conducted the experiment. All authors contributed to the article and approved the submitted version.

\section{FUNDING}

This research was supported by the National Natural Science Foundation of China (31660277) and Guangxi Natural Science Foundation (2016GXNSFAA380239). 


\section{REFERENCES}

Arnau, A., Espaulella, J., Serrarols, M., Canudas, J., Formiga, F., and Ferrer, M. (2016). Risk factors for functional decline in a population aged 75 years and older without total dependence: a one-year follow-up. Arch. Gerontol. Geriatr. 65, 239-247. doi: 10.1016/j.archger.2016.04.002

Bielak, A. A. M., Cherbuin, N., Bunce, D., and Anstey, K. J. (2014). Preserved differentiation between physical activity and cognitive performance across young, middle, and older adulthood over 8 years. J. Gerontol. Ser. B 69, 523-532. doi: 10.1093/geronb/gbu016

Boyle, P., Wilson, R., Aggarwal, N., Tang, Y., and Bennett, D. (2006). Mild cognitive impairment: risk of Alzheimer disease and rate of cognitive decline. Neurology 67, 441-445. doi: 10.1212/01.wnl.0000228244.10416.20

Bubbico, G., Chiacchiaretta, P., Parenti, M., Di Marco, M., Panara, V., Sepede, G., et al. (2019). Effects of second language learning on the plastic aging brain: functional connectivity, cognitive decline, and reorganization. Front. Neurosci. 13:423. doi: 10.3389/fnins.2019.00423

Calasanti, T. (2016). Combating ageism: how successful is successful aging? Gerontol. 56, 1093-1101. doi: 10.1093/geront/gnv076

Campbell, D. T. (1958). Common fate, similarity, and other indices of the status of aggregates of persons as social entities. Behav. Sci. 3, 14-25. doi: 10.1002/bs. 3830030103

Charness, N., and Boot, W. R. (2009). Aging and information technology use: potential and barriers. Curr. Direct. Psychol. Sci. 18, 253-258. doi: 10.1111/j. 1467-8721.2009.01647.x

Chongsuvivatwong, V. (2007). Analysis of Epidemiological Data Using $R$ and Epicalc. Thailand: Epidemiology Unit Prince of Songkla University. (pp. 1-314)

Clare, L., Wu, Y.-T., Teale, J. C., MacLeod, C., Matthews, F., and Brayne, C. (2017). Potentially modifiable lifestyle factors, cognitive reserve, and cognitive function in later life: a cross-sectional study. PLoS Med. 14:e1002259. doi: 10. 1371/journal.pmed.1002259

Colcombe, S. J., Erickson, K. I, Scalf, P. E., Kim, J. S., Prakash, R., McAuley, E., et al. (2006). Aerobic exercise training increases brain volume in aging humans. J. Gerontol. Ser. A 61, 1166-1170. doi: 10.1093/gerona/61.11.1166

Dardiotis, E., Kosmidis, M. H., Yannakoulia, M., Hadjigeorgiou, G. M., and Scarmeas, N. (2014). The Hellenic Longitudinal Investigation of Aging and Diet (HELIAD): rationale, study design, and cohort description. Neuroepidemiology 43, 9-14. doi: $10.1159 / 000362723$

Deary, I. J., Corley, J., Gow, A. J., Harris, S. E., Houlihan, L. M., Marioni, R. E., et al. (2009). Age-associated cognitive decline. Br. Med. Bull. 92, 135-152.

Folstein, M., Anthony, J. C., Parhad, I., Duffy, B., and Gruenberg, E. M. (1985). The meaning of cognitive impairment in the elderly. J. Am. Geriatr. Soc. 33, 228-235. doi: 10.1111/j.1532-5415.1985.tb07109.x

Folstein, M. F., Folstein, S. E., and McHugh, P. R. (1975). "Mini-mental state": a practical method for grading the cognitive state of patients for the clinician. J. Psychiatr. Res. 12, 189-198.

Friedman, D. B., Becofsky, K., Anderson, L. A., Bryant, L. L., Hunter, R. H., Ivey, S. L., et al. (2015). Public perceptions about risk and protective factors for cognitive health and impairment: a review of the literature. Int. Psychogeriatr. 27, 1263-1275. doi: 10.1017/s1041610214002877

Fung, A. W.-T., Leung, G. T.-Y., and Lam, L. C.-W. (2011). Modulating factors that preserve cognitive function in healthy ageing. East Asian Arch. Psychiatry $21,152-156$.

Ganguli, M., Vander Bilt, J., Saxton, J., Shen, C., and Dodge, H. (2005). Alcohol consumption and cognitive function in late life: a longitudinal community study. Neurology 65, 1210-1217. doi: 10.1212/01.wnl.0000180520. 35181.24

Gregory, M. A., Gill, D. P., and Petrella, R. J. (2001). Brain health and exercise in older adults. Curr. Sports Med. Rep. 12, 256-271.

Guralnik, J. M., LaCroix, A. Z., Abbott, R. D., Berkman, L. F., Satterfield, S., Evans, D. A., et al. (1993). Maintaining mobility in late life. i. demographic characteristics and chronic conditions. Am. J. Epidemiol. 137, 845-857. doi: 10.1093/oxfordjournals.aje.a116746

Heinzel, S., Schulte, S., Onken, J., Duong, Q.-L., Riemer, T. G., Heinz, A., et al. (2014). Working memory training improvements and gains in non-trained cognitive tasks in young and older adults. Aging Neuropsychol. Cogn. 21, 146-173. doi: 10.1080/13825585.2013.790338
Hughes, T. F., and Ganguli, M. (2009). Modifiable midlife risk factors for latelife cognitive impairment and dementia. Curr. Psychiatry Rev. 5, 73-92. doi: $10.2174 / 157340009788167347$

Klimova, B., Valis, M., and Kuca, K. (2017). Cognitive decline in normal aging and its prevention: a review on non-pharmacological lifestyle strategies. Clin. Int. Aging 12, 903-910. doi: 10.2147/cia.s132963

Lamblin, M., Murawski, C., Whittle, S., and Fornito, A. (2017). Social connectedness, mental health and the adolescent brain. Neurosci. Biobehav. Rev. 80, 57-68. doi: 10.1016/j.neubiorev.2017.05.010

Livingston, G., Sommerlad, A., Orgeta, V., Costafreda, S. G., Huntley, J., Ames, D., et al. (2017). Dementia prevention, intervention, and care. Lancet 390, 2673-2734.

McAuley, E., Konopack, J. F., Motl, R. W., Morris, K. S., Doerksen, S. E., and Rosengren, K. R. (2006). Physical activity and quality of life in older adults: influence of health status and self-efficacy. Ann. Behav. Med. 31, 99-103. doi: 10.1207/s15324796abm3101_14

McAuley, E., and Rudolph, D. (1995). Physical activity, aging, and psychological well-being. J. Aging Phys. Act. 3, 67-96. doi: 10.1123/japa.3.1.67

Mensink, G. B., Loose, N., and Oomen, C. M. (1997). Physical activity and its association with other lifestyle factors. Eur. J. Epidemiol. 13, 771-778.

Molloy, D. W. (2014). [[Au Query:

Please provide Accessed date for the reference "Molloy, 2014."]] Standardised Mini-Mental State Examination (SMMSE):Guidelines for administration and scoring instructions. Available online at: https://www.ihpa.gov.au/what-we-do/ standardised-mini-mental-state-examination-smmse

Pagliaro, S., Alparone, F. R., Picconi, L., Paolini, D., and Aquino, A. (2013). Group based resiliency: contrasting the negative effects of threat to the ingroup. Curr. Res. Soc. Psychol. 21, 35-41.

Perna, L., Mielck, A., Lacruz, M. E., Emeny, R. T., Holle, R., Breitfelder, A., et al. (2012). Socioeconomic position, resilience, and health behaviour among elderly people. Int. J. Public Health 57, 341-349. doi: 10.1007/s00038-0110294-0

Plassman, B. L., Williams, J. W., Burke, J. R., Holsinger, T., and Benjamin, S. (2010). Systematic review: factors associated with risk for and possible prevention of cognitive decline in later life. Ann. Int. Med. 153, 182-193. doi: 10.7326/00034819-153-3-201008030-00258

Roberts, R. O., Cha, R. H., Mielke, M. M., Geda, Y. E., Boeve, B. F., Machulda, M. M., et al. (2015). Risk and protective factors for cognitive impairment in persons aged 85 years and older. Neurology 84, 1854-1861. doi: 10.1212/wnl. 000000000001537

Rocca, W. A., Petersen, R. C., Knopman, D. S., Hebert, L. E., Evans, D. A., Hall, K. S., et al. (2011). Trends in the incidence and prevalence of Alzheimer's disease, dementia, and cognitive impairment in the United States. Alzheimers Dement 7, 80-93. doi: 10.1016/j.jalz.2010.11.002

Rohrer, J. E., Pierce, J. R. Jr., and Blackburn, C. (2005). Lifestyle and mental health. Prev. Med. 40, 438-443.

Ruuskanen, J. M., and Ruoppila, I. (1995). Physical activity and psychological well-being among people aged 65 to 84 years. Age Ageing 24, 292-296. doi: 10.1093/ageing/24.4.292

Salmon, P. (2001). Effects of physical exercise on anxiety, depression, and sensitivity to stress: a unifying theory. Clin. Psychol. Rev. 21, 33-61. doi: 10. 1016/s0272-7358(99)00032-x

Satizabal, C. L., Beiser, A. S., Chouraki, V., Chêne, G., Dufouil, C., and Seshadri, S. (2016). Incidence of dementia over three decades in the framingham heart study. N. Engl. J. Med. 374, 523-532. doi: 10.1056/nejmoa 1504327

Scarmeas, N., Anastasiou, C. A., and Yannakoulia, M. (2018). Nutrition and prevention of cognitive impairment. Lancet Neurol. 17, 1006-1015. doi: 10. 1016/s1474-4422(18)30338-7

Scazufca, M., Almeida, O. P., and Menezes, P. R. (2010). The role of literacy, occupation and income in dementia prevention: the São Paulo Ageing \& Health Study (SPAH). Int. Psychogeriatr. 22, 1209-1215. doi: 10.1017/ s1041610210001213

Uffelen, J. G. Z. V., Chin A Paw, M. J. M., Hopman-Rock, M., and Mechelen, W. V. (2008). The effects of exercise on cognition in older adults with and without cognitive decline: a systematic review. Clin. J. Sport Med. 18, 486-500. doi: $10.1097 /$ jsm.0b013e3181845fob

Walsh, R. (2011). Lifestyle and mental health. Am. Psychol. 66, 579-592. 
Wang, J. Y. J., Zhou, D. H. D., Li, J., Zhang, M., Deng, J., Tang, M., et al. (2006). Leisure activity and risk of cognitive impairment: the chongqing aging study. Neurology 66, 911-913. doi: 10.1212/01.wnl.0000192165. 99963.2a

Wei, G.-X., Dong, H.-M., Yang, Z., Luo, J., and Zuo, X.-N. (2014). Tai Chi Chuan optimizes the functional organization of the intrinsic human brain architecture in older adults. Front. Aging Neurosci. 6:74. doi: 10.3389/fnagi.2014. 00074

Xu, J., Wang, J., Wimo, A., Fratiglioni, L., and Qiu, C. (2017). The economic burden of dementia in China, 1990-2030: implications for health policy. Bull. World Health Organ. 12, 256-271.

Zhang, M., Jing, D., Liu, Y., Ning, S., Li, G., Yang, F., et al. (2017). Prevalence, incidence, risk and protective factors of amnestic mild cognitive impairment in the elderly in shanghai. Curr. Alzheimer Res. 14, $460-466$.

Conflict of Interest: The authors declare that the research was conducted in the absence of any commercial or financial relationships that could be construed as a potential conflict of interest.

Copyright (C) 2020 Yan, Zou and Hou. This is an open-access article distributed under the terms of the Creative Commons Attribution License (CC BY). The use, distribution or reproduction in other forums is permitted, provided the original author(s) and the copyright owner(s) are credited and that the original publication in this journal is cited, in accordance with accepted academic practice. No use, distribution or reproduction is permitted which does not comply with these terms. 